\title{
TALENT MANAGEMENT EFFICIENCY IN SUCCESSION PLANNING: A PROPOSED MODEL FOR PHARMACEUTICAL COMPANIES
}

\author{
Dr. Poonam Jindal \\ Assistant Professor, VJIM, Hyderabad, India \\ Dr. Mohsin Shaikh \\ ASM group of institutes, India
}

\begin{abstract}
Buying talent is always costlier than developing talent pool. Pharmaceutical companies struggle for retaining the best talent to make their succession plan successful. If right talent management strategies (TMS) are used to attract, develop, and retain the best talent, the talent pool can be created. Thus, the succession plan will become reality. This paper is based on the vast and extensive literature review about TMS and their use in attracting, developing, and retaining best talent. By developing a hypothetical model, the researcher has found the impact of TMS on succession planning. The article further suggests the scope of empirical study to test and prove the hypothetical model. Model suggests that the right Talent identification and development strategies lead to talent retention and that brings successful succession planning in place.
\end{abstract}

Key words: Talent Management Strategies, Talent Development, Talent Retention, Succession Planning, Talent Management.

Cite this Article: Poonam Jindal and Mohsin Shaikh, Talent Management Efficiency in Succession Planning: A Proposed Model for Pharmaceutical Companies, International Journal of Management, 11(12), 2020, pp203-213. http://iaeme.com/Home/issue/IJM?Volume=11\&Issue=12

\section{INTRODUCTION}

Buying talent is always costlier that developing your own. Especially for the sectors having tremendous growth, such as pharmaceutical, the competition for retaining the best talent is high. The growth of any organization depends on its star performers. Companies have huge opportunities for talent and are ready to pay higher remunerations and facilities to compete in this VUCA (volatile, uncertain, complex, ambiguous) environment. This tendency of companies to poach the best talent creates insecurity in the minds of employees and employer both. A situation may arise when a senior talent leaves the company over- night and joins its 
competitor and, in some cases, when a senior leader leaves an organization, many of his/her team members move with him/her which results in a loss of talent to the organization.

Current trend shows that employees are least interested to have a long-term bond with the companies and vice-versa. Companies also remove people if they feel there is no necessity of those people. Attrition is addressed as a problem in the current business world, but every time it is not bad which is also clear to corporate world. Companies identify the competencies of their employees to get the best out of them in more than one role. For example, a person works in the HR department and he/she also has a good knowledge of data analytics will be preferred candidate by any company. The task of succession management becomes easy if various talents with such competencies are available within the company.

Succession management is considered a planned job of organizations to secure the continuity of talent in key positions, to boost individual development and to groom talent within the company. The companies must identify the key jobs and the key performers to continue those key jobs whenever there is a vacancy. In a nutshell, succession planning and management is a combination of identifying key jobs and developing talent to replacement. Companies who can do this, as and when needed, are successful.

The war for talent is at its highest level even in pharmaceutical companies. Pharmaceutical business needs to invest more in the development and retention of talent. As pharmaceutical industry is expanding globally, the reactive approach will not be helpful. Companies must be proactive in their approach for talent management.

The key factors for securing top talent for pharmaceutical are developing talent pipeline, having market and competitors' knowledge, taking care of candidates experience in the initial contacts, continuous mentoring, regular dialogue, internal career development opportunities, engagement and many more.

\section{REVIEW OF LITERATURE}

The review of literature is done to explore the meaning and different point of views about talent management, talent management strategies and succession planning. It then proceeds to explore the vast literature available and research work done by many scholars and organizations regarding the use of talent management and succession planning and management which can lead to formations of a hypothetical model.

\subsection{Talent Management:}

A 2020 search for the word "talent management" on Google discovered about 76,10,00,000 outcomes, with talent management tools, talent management strategies, talent management softwares, talent management solutions, and talent management guides etc leading numerous HRM publications and websites. In spite of this deceptive status, and numerous other HRM activities, a detailed definition of talent management is still fairly vague. Moreover, there seems to be a disconnect between the commitment with which talent management is being preached by practitioners and it being handled within the academic community.

An extensive and critical literature review of talent management by Lewis and Heckman (2006), found lot of confusion and lack of clarity in defining Talent management. TM is identified in three main concepts such as:

- TM is "a collection of typical human resource department practices...such as recruiting, selection, development and career and succession management". (Lewis and Heckman, p. 140). This means TM is extension over HRM, only as a term used 
and the responsibilities are same as HRM, only with more use of technology to carry these functions.

- The second concept emphases on forecasting or indicating the movement of people throughout the organization, based on the factors such as labour market, required skills and growth, and attrition rate. This perspective reflects as talent management is mostly synonymous of human resource planning.

- Third perspective of TM focuses on attracting, developing, and retaining talent. In the report of Conference Board, talent was defined as "individuals who have the capability to make a significant difference to the current and future performance of the company" (Morton, 2004, p. 6).

- The third approach can be seen through case studies and examples of organizations where high performing employees are treated as talent and use of this approach is reportedly seen in profitability and sales gains. This was understood in the work done by Handfield-Jones et al. (2001), later it was discounted on its efficacy (Lewis and Heckman, 2006).

- Whelan, Collings, \& Donnellan (2009) add the fourth idea of thought on TM, which focuses mainly on identification of vital positions that can influence the competitive growth of the company. Boudreau \& Ramstad (2005, p. 129) also belong to this fourth category of idea: they also argue that all the traditional and old HR actions need to be stretched into a decision skill called "Talentship", where they suggest organizations to "identify critical talent pools" where the availability and the quality of human resource make the biggest difference to the planned success of the organization. The talent pools are defined as jobs, roles or competencies. It links the connection between talent management strategies used and the competitive advantages within the organizations. (Collings \& Mellahi, 2009).

- According to Cappelli (2008), talent management is a device for companies to attain their overall aims and goals like earning money and profits. So, he says that the organizations need to analyse and recognize the benefits and the costs involved in talent management and their choices. Research indicates that engagement activities (Jindal and Shaikh,2016) and well-being activities (Jindal and Veda, 2020) work as talent management strategies in hospitality sector.

- According to Nick Stephens, 2010, the four key ways to retain competitive advantage through TM was found to be

- Leadership Development

- High Potential Employee Identification and Assessment

- Performance Management

- Succession Planning

A theoretical framework has been provided that could help researchers in designing their research plans in the area and encourage to help managers to engage with some of the problems they face with respect to manage the talent in the organization. While extensive research has been undertaken on talent management as the HR ingenuity (Scullion et al., 2010), 


\subsection{Succession planning}

Succession planning is not only useful in large global corporations, all companies (large and small) can benefit from the process. Orellano \& Miller (1997) state that the three basics of succession planning include:

- Identifying key management positions within the company,

- Identifying upcoming vacancies in key positions,

- Identifying employees who would become the right fit into vacancies.

Changes like removing old process and procedures have to be taken place for successful workforce succession planning. Morfeld explains, (2005) that the approach is a multi-step process with systematic way which comprises attainment of a systematic planning of the present human resource, foreseeing the environment that will work in the future too, identification of the competencies that will be needed in future to grow the company and grab those future prospects and succeed, and finally developing those strategies for creating that future labor force. Huxtable\&Cheddie (2001) emphasis on the status and hierarchy of the human resource functions as situated in the organization. Companies preserve the HRM that plays an important and strategic role and able to produce the data and analyse it, to produce results. Apart from this as per the size of the company and the nature of the staff and budgetary limitations, a specialist in succession planning may need to be found to start and later manage the whole process.

Creating the succession planning at leadership roles then becomes needed and a critical distinction point. This is probably possible through developing pools of talent, development of a talent mindset, identifying critical positions, and differentiating between star performers and others in terms of potential and performance. Conger and Fulmer, (2003) say that besides these given points, creating essential positions and fulfilling them through nonstop learning by bouncing targets is another strategy of developing leadership pipeline. Boudreau and Ramstad (2005) say it "talent segmentation" which is as important as "customer segmentation'. Talent segmentation is recognizing the key talent pools- where talent makes the major difference to premeditated success.

Mostly organizations do not have an operational way and process in place for succession planning for the position of CEO or any other executive. The problem could be that most of organizations do not have sufficient time to identify and groom the successors and there are no honest and open discussions about executive performance.

Organizations mostly design for succession planning, to decrease the risk, rather getting the best successors, which is just a groundwork for the future success. They only emphasize on the minimising the risk and loss aspects rather than creating elements for value creation for succession of the organization.

Defined roles are generally not followed within the organization, because they approve that succession planning comprises the mutual efforts of all stakeholder such as the senior management team, the board of directors, and support staff like human resources department. However, the KPOs of an executive's performance focus on effectively managed succession by determining accurate organizational metrics overall and do not measure the effectiveness in grooming and mentoring of them.

Succession plans are very much different when compared to coaching and internal talent development programs which progressively develop the leadership competencies. Hence because of this, the board of directors does not have adequate understanding of the competencies and capabilities required by the senior management team and to decide which 
executives are the most qualified to replace an outgoing CEO or senior member whenever a succession occurs in the organization.

Succession is not defined to be happening at different times. It is a continuous and comprehensive process where management and the board of directors prepare for transitions at any time and at multiple levels throughout the organization which includes not only for the CEO position, but also for their direct reports and other critical positions. This is because succession planning is more time-consuming, riskier, and more expensive when carried out slowly rather than in advance.

One of the biggest reasons why organizations fail at succession is that they do not assign ownership and accountability to the defined process.

The succession planning programs should not be isolated, but it should strategically support one another. By connecting CEO and senior executive succession plans with coaching and internal talent development, the only way to have a reliable succession plan is to map succession to the pipeline of internal talent and identify the possible hurdles and implement development plans accordingly.

Coaches and mentors should be assigned because they bring an outsiders perspective and the degree of objectivity to the development process within the organization. They also allow for executives to grow outside and the board mentors can give senior executives a new perspective of the organizational performance.

\section{Talent Management and Succession Planning}

Succession planning is not only useful in large global corporations, all companies (large and small) can benefit from the process. Orellano \& Miller (1997) explain that the three basics of succession planning include:

- Identification of critical management positions within the organization,

- Identification of future vacancies in those positions,

- Identification of managers who would potentially fit into these vacancies.

Huxtable \& Cheddie (2001) emphasis upon the importance of the level of the human resource functions as placed in the organization. They preserve the human resource management that plays a strategic role and has the capability to yield the data and the analyse it to produce results. Depending on the size and the expertise of the company's own staff and budgetary limitations, a succession planning specialist may need to be found to start or manage the entire process.

According to Angela Hills, Senior Vice President, Blessing White, some ponder upon it like the royal succession to the throne planning who will be the next heir (senior team). Whereas for other employees in the company to help people cross-skill so that there is a wellequipped talent pool who are suitable and experienced talent for internal recruitment. For some it is the strategy for entire organization which is focused on ensuring the organization to be "future-proofed" so that it will help the right skills in to grow and perform in a future that is increasingly unpredictable.

Rothwell (2010) defines succession planning and management as "any effort designed to ensure the continued effective performance of an organization, division, department or work group by making provision for the development, replacement and strategic application of key people over time."

To put it simply, it does everything to ensure that you have the right people for the right job at the right time. 
McKinsey developed a model for GE to segment its talent into nine categories, that provides a segmentation of talent and helps taking decision about the identification, development and retention of talent. The given image expresses the 9-box matrix of GE's employee segmentation. (Davies, 2010).

Creating the succession planning at leadership roles then becomes needed and a critical distinction point. This is probably possible through developing pools of talent, development of a talent mindset, identifying critical positions, and differentiating between star performers and others in terms of potential and performance. Conger and Fulmer, (2003) say that besides these given points, creating essential positions and fulfilling them through nonstop learning by bouncing targets is another strategy of developing leadership pipeline. Boudreau and Ramstad (2005) say it "talent segmentation" which is as important as "customer segmentation". Talent segmentation is recognizing the key talent pools- where talent makes the major difference to premeditated success.

Successful workforce planning may include far-reaching changes to old processes and procedures. This approach is organized and a process of multi levels, which includes attainment of a exhaustive understanding of the current human resource, identifying the skills needed that will move the company forward to grab future opportunities and thrive, foreseeing the operating condition that will exist in the future, and developing strategies for building that future employees (Morfeld, 2005).

In the context of Knowledge Management, succession planning concentrates on how the organization plans to substitute key knowledge containers and to ensure that high potential successors are being ready to fill these vital roles in the organization (Bersin, 2006; Debowski, 2006; Lengnick-Hall and Andrade, 2008).

The role of Talent Management in Succession planning and leadership development involves preparing for the organization's next senior team and in developing a talent pool for internal recruitment by cross skilling employees and to ensure that the organization is future ready with respect to skills availability as whenever needed (Hills, 2009).

Succession planning not only involves continuous identification, training and promoting employees with the perspective of preventing corporate knowledge, but also identifying essential competencies and communicating those skills (Jones, 2008). Talent Management needs a continuous training and developing high performers for potential new roles, to identify the knowledge gaps among employees and to implement initiatives to enhance their competencies and ensure that they retain for longer period (Cairns, (2009), Hills (2009).

A four-quadrant model was proposed by Iles et al. (2010). There are 4 main perspectives on Talent management which were

- "exclusive-people: focused on "key" people with high performance

- exclusive position: focused on right people in key roles or positions

- inclusive people: everyone seems potentially talented

- social capital: focused on teams, cultures, and networks".

A survey done by SHRM found that large organizations (500 and more employees) are mainly having formal succession planning. According to most respondents' viewpoint and organizational documents, the following 3 processes were stated as the key mechanisms of talent management:

- Talent acquisition: it is process of identifying talent within or outside the organization and attracting them by using assessment and development centers. 
- Talent development: after recognizing latent talents, training programs are offered to develop their skills.

- Talent retention: developed and talented employees will be poached fast by the competitors. So organizations have to have proper processes to retain these talented employees. Therefore, retaining schemes to retain talents is one of the foremost mechanisms of talent management systems.

\subsection{Developing Talent Strategy for succession planning}

Three key areas to get right the talent strategy are (Jan Hills, 2012),

- Identifying the required traits that qualify people to carry and achieve the business strategy and generating the right talent philosophy to use these traits and skills.

- Preparing people manager to work on nurturing the best talent and getting the most out of them.

- Finally, the results those are achieved by the execution of business strategy through the talent strategy should be managed. Hiring in a key skill whenever recruitment is required this is one approach to succession planning i.e. to buy talent and the other way is to build it from within. Therefore, we can say that the succession strategy will be a mix of buying and building talent.

\subsection{Five significant systems for making succession planning strategy work}

- Demonstrate the future of the organization.

- The 3Cs of fit: competence, connection and culture.

- The magic mix works when developing people for succession, a mix of experience, coaching and formal learning.

- Involve the talent in the organizational planning.

- Cast a wider net, not only fill look into jobs and the options to fill them but see the strength of you people and create role for them. For example if an employee is great at sales and consulting, create a role for him.

In-depth interviews conducted by The Institute of Executive Development and the Rock Centre for Corporate Governance with executives and directors at 20 companies in the year 2013 regarding their succession planning and executive development strategies. Succession planning in the organizations became important because they often are not aware about the replacement available to fill senior level executive vacancies. Organizations generally do not make the appropriate connect between the experiences and skills essential to run the company and the applicants either internally or externally available and are best suited to take over senior level positions. Therefore, when a list of potential successors is made, it often has a slight scope for which we cannot rely on when the succession event occurs.

Each position in the senior management team including CEO, requires a set of skills and capabilities related to the scope of responsibility towards the organizational strategy. They must be evaluated on both current and future perspectives. After identifying the gaps in future need and the current available leadership skills, strategies should be planned to rectify and fill in the gap by providing the facilities such as development activities or job rotation. Even more wider plans like creating jobs for available skill sets or competencies can be implemented. Staying competent in changing world gives competitive advantage in the market.

Each organization's succession plan should be so tailored to take into account its exact competitive situation, future need and strategy, and depth of talent. 


\subsection{Talent management and succession planning in pharmaceutical companies:}

Talent Management has become an important buzzword in business, more so in emerging sector like Pharmaceutical during the recent past.

Without any question, effective talent management delivers the most critical point of strategic force today. TM by offering enormous business values, is complex and continually evolving. It is influenced by external factors such as the global expansion, the economy, and mergers and acquisitions etc. The main success factors for effective talent management include active top management and CEO participation, alignment with strategic goals, and HR management. As time goes on, the other themes of TM are evolving such as role of managers in talent development, importance of culture, process, and involvement of top management etc. (Morton, L 2004).

Indian pharmaceutical industry is known for change. Enactment in early 2005 of patent protections that comply with the World Trade Organization's Agreement on Trade-Related Aspects of Intellectual Property Rights(TRIPS) has brought India to the front of latent outsourcing locations for the world's pharmaceutical multinational corporations(MNCs). The question now is: will India's pharmaceutical firms soon rival the country's information technology businesses as outsourcing powerhouses? Will they grow to compete with Big Pharmaceutical in developing new medicines? For this to happen, these companies must focus a lot on developing the talent of their workforce. Employee engagement becomes tool for talent retention, hence develops succession plan in pharmaceutical companies (Jindal et al, 2017). Talent Management plays a key role in creating, developing, and sustaining a competitive advantage for any pharmaceutical company (Cheryl Buxton et. al, 2005). Therefore, this study of TM in pharmaceutical companies becomes an important contribution to the existing literature.

Profits of the company equally depend on customer and employee retention. Satisfied employees create pool of satisfied customers. The technical expertise of pharmaceutical employees is key for success of pharmaceutical companies. (Majumdar, 2009). This industry cannot afford to miss its talent in the era of war for talent. Attracting, developing, and retaining talent is required for the suave functioning of this industry. Usually the management remains incapable to place right talent at right position, as every person cannot handle every position of the organization but possesses specialization in some specific area. It is the responsibility of the management to find the perfect fitment between the person and position where one can be best suited in view of experience and expertise. It is not the fault of any talented person for not yielding perfect performance, but management must assess the potential of the person within the total organizational set up.

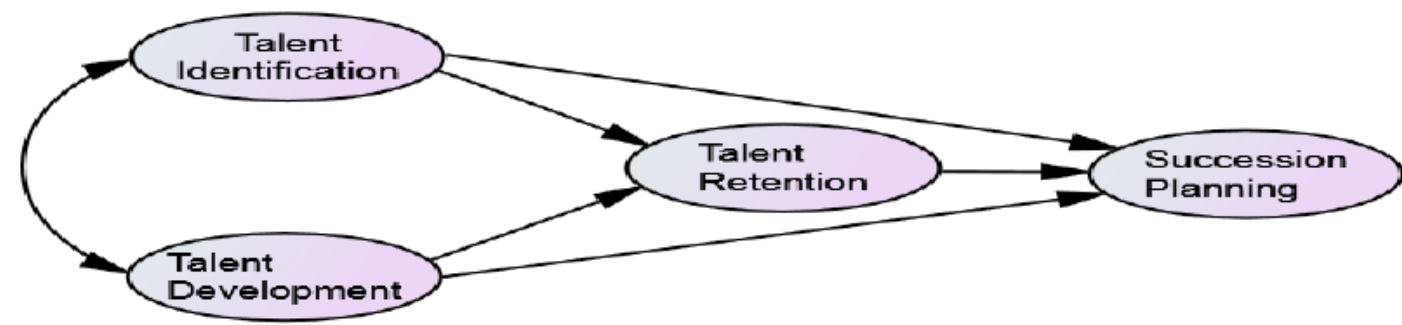

Figure. 1 Hypothetical Model

Based on the literature review a hypothetical model is developed as shown in Figure 1. 
In today's competitive global economy, companies must continually invest in human capital. HR leaders, in the role of business partners must work closely with senior management to identify, attract, select, develop and retain talent. Yet the talent shortage presents both cultural challenges and socio-economic as talent across borders. Thus, in view of diversity in workforce trends such as generations (Jindal and Shaikh, 2017), the aging workforce, global supply, and increasing global mobility, progress-looking organizations must rethink their approach to talent management to best connect talent. By doing so, they will be positively placed to succeed in a highly competitive market. In addition, organizational culture, succession planning, leadership development and employee engagement have a significant impact on talent retention. By considering these factors, a unified approach to talent management offers a way toward sustaining excellent business results. As a reaction to the condition, strategic talent management is becoming main motivation of the organizations.

\section{LIMITATIONS AND FUTURE RESEARCH SUGGESTIONS:}

This article provides an insight to pharmaceutical companies about their TM strategies and its impact on their succession planning. But the suggested model has some limitations as the model is not supported by some empirical evidence. The developed model is based on the literature review in the field and there is no empirical study done to support the model. The future research scope is there to test hypothetical model with the help of using statistical tools and techniques after collecting data. Data can be collected from the pharmaceutical companies about their practices and strategies for talent management.

\section{CONCLUSION:}

The pharma industry is one of the industries who are struggling with talent retention issues, and without retaining the best talent succession planning cannot be planned. Continuous hiring for required leaders will not help in winning the war for talent. The succession planning and management in pharmaceutical industry needs strong TM strategies to be implemented. This model suggests the right strategies for succession planning in pharma with the help of literature review though, but another article can focus on the empirical and statistically proven study. Such research would become a guide for pharma companies to develop their succession plans.

\section{REFERENCES:}

[1] Bassett, P., Buxton, C., Pathania, R., \& Sharan, M. (2005). Talent Management Is Key to India's Pharma Futurell. Korn/Ferry International.

[2] Boudreau, J. W., \& Ramstad, P. M. (2005). Talentship, talent segmentation, and sustainability: A new HR decision science paradigm for a new strategy definition. Human Resource Management: Published in Cooperation with the School of Business Administration, The University of Michigan and in alliance with the Society of Human Resources Management, 44(2), 129-136.

[3] Buckley, P., Viechnicki, P., \& Barua, A. (2016). The 2016 Deloitte Millennial Survey: Winning over the next generation of leaders.

[4] Cairns, T. D. (2009). Talent management at homeland security: a corporate model suggests a recipe for success. Employment Relations Today, 36(3), 19-26.

[5] Cappelli, P. (2008). Talent on demand. Harvard Business School Publishing, Boston, MA.

[6] Chitsaz-Isfahani, A., \& Boustani, H. R. (2014). Effects of talent management on employee's retention: The mediate effect of organizational trust. International Journal of Academic Research in Economics and Management Sciences, 3(5), 114. 
[7] Collings, D. G., \& Mellahi, K. (2009). Strategic talent management: A review and research agenda. Human resource management review, 19(4), 304-313.

[8] Conger, J. A., \& Fulmer, R. M. (2003). Developing your leadership pipeline. Harvard business review, 81(12), 76-85.

[9] Davies, B., \& Davies, B. J. (2010). Talent management in academies. International Journal of Educational Management, 24(5), 418-426.

[10] Farndale, E., Scullion, H., \& Sparrow, P. (2010). The role of the corporate HR function in global talent management. Journal of world business, 45(2), 161-168.

[11] Fegley, S. (2006). 2006 Talent Management: Survey Report. Society for Human Resource Management.

[12] Groves, K. S. (2007). Integrating leadership development and succession planning best practices. Journal of management development, 26(3), 239-260.

[13] Handfield-Jones, H., Michaels, E., \& Axelrod, B. (2001). Talent management: A critical part of every leader's job. Ivey Business Journal, 66(2), 53-53.

[14] Hills, A. (2009). Succession planning-or smart talent management?. Industrial and commercial Training, 41(1), 3-8.

[15] Hills, J. (2012). Neuroscience and talent: How neuroscience can increase successful execution of talent strategy. Human Resource Management International Digest, 20(3), 34-37.

[16] Hirsh, W. (2000). Succession planning demystified. Brighton: Institute for Employment Studies.

[17] Iles, P., Chuai, X., \& Preece, D. (2010). Talent management and HRM in multinational companies in Beijing: Definitions, differences and drivers. Journal of World Business, 45(2), 179-189.

[18] Jindal, M. P., \& Shaikh, M. (2016). Talent Management through Employee Engagement in Hospitality Companies. Int. J. of Multidisciplinary and Current research, 4.

[19] Jindal, P., Shaikh, M., \& Shashank, G. (2017). Employee engagement; tool of talent retention: Study of a pharmaceutical company. SDMIMD Journal of Management, 8(2), 7-16.

[20] Jindal, P., \& Shaikh, M. (2017). Developing and managing young talent: framework of talent management strategies for Gen Y. International Journal of Environment, Workplace and Employment, 4(3), 171-185.

[21] Jindal, P., \& Srujana, V. (2020). A STUDY OF EMPLOYEE'S PERCEPTION ON WELLBEING POLICIES IN HOTEL INDUSTRY. Prerana, Journal of management thought and practice, 12 (2), 23-31.

[22] Jones, C. B. (2008). Chief nursing officer retention and turnover: a crisis brewing? Results of a national survey. Journal of Healthcare Management, 53(2).

[23] Kowalewski, S. J., \& Moretti, L. SUCCESSION PLANNING: CURRENT AND FUTURE. ISSN 1931-0285 CD ISSN 1941-9589 ONLINE, 76.

[24] Larcker, D. F., \& Saslow, S. (2014). Reports on senior executive succession planning and talent development. Institute of executive development and Stanford University.

[25] Lewis, R. E., \& Heckman, R. J. (2006). Talent management: A critical review. Human resource management review, 16(2), 139-154.

[26] Majumdar, D. M. (2007). Talent Retention in Pharmaceutical Company: A Perspective in the Modern Era. International Research Journal-ISSN-0974-2882Vol. II, (7).

[27] Morfeld, C. (2005). Workforce planning: the strategy behind "strategic staffing". SHRM online.

[28] Morton, L. (2004, January). Integrated and integrative talent management: A strategic HR framework. New York, NY: Conference Board.

[29] Orellano, T., \& Miller, J. (1997). Succession planning: Lessons from Kermit the frog. SHRM HR Resources Information Center. 
[30] Pruis, E. (2011). The five key principles for talent development. Industrial and commercial training, 43(4), 206-216.

[31] Rothwell, W. (2010). Effective succession planning: Ensuring leadership continuity and building talent from within. Amacom.

[32] Stephens, N. (2010). Talent management: ensuring your people give you the competitive edge. Strategic Direction, 26(7), 3-5.

[33] Stroup, C., \& Zheng, H. (2016). What are Key Emerging, Employee-Facing Trends in HR that will be Influential in Attracting and Retaining Future Top Talent?.

[34] Watson, W. T. (2016). Employee value proposition and total rewards: Modernize or risk irrelevance: Findings from the 2016 global talent management \& rewards and global workforce studies-US healthcare providers.

[35] Whelan, E., \& Carcary, M. (2011). Integrating talent and knowledge management: where are the benefits?. Journal of Knowledge Management, 15(4), 675-687.

[36] Whelan, E., Collings, D., \& Donnellan, B. (2009, November). An examination of talent management concepts in knowledge intensive settings. In International Conference on Knowledge Science, Engineering and Management (pp. 450-457). Springer, Berlin, Heidelberg.

[37] https://www.pmi.org/learning/thought-leadership/series/talent-management/poweringstrategic-initiatives-pmo

[38] https://www.edenhousesolutions.co.uk/wp-content/uploads/2016/03/White-PaperSuccession-Management-more-than-a-plan.pdf

[39] https://www.successfactors.com/static/docs/sfguidesuccessionplanningr3.pdf 